\title{
Correction to: Does the Size of a Fashion Model on a Retailer's Website Impact the Customer Perceived Attractiveness of the Model and Purchase Intention? The Role of Gender, Body Satisfaction and Congruence
}

Anik St-Onge, Aurelie Merles, Florian Pichonneau, and Sylvain Sénécal

Correction to:

Chapter 22 in: J. Bellemare et al. (eds.), Managing Complexity, Springer Proceedings in Business and Economics, https://doi.org/10.1007/978-3-319-29058-4_22

The book was inadvertently published with the following error and it has been corrected now:

On Page 284, Section 22.4 has been removed and the next section is renumbered consecutively as Section 22.4 . 